\title{
ANALISIS KOHESI LEKSIKAL DALAM MAJALAH PATRIOTIK LPM UNIVERSITAS BATANGHARI EDISI XVI JULI-SEPTEMBER TAHUN 2016
}

\author{
Erik Pernando, Ade Rahima \\ FKIP Universitas Batanghari Jambi \\ e-mail: pernandoerik35@yahoo.co.id
}

The purpose of this research is to describe the lexical cohesion in Patriotik LPM Batanghari University edition July-September 2016. This research uses descriptive qualitative approach. The data is taken from the texts in Patriotik magazine edition XVI July-September 2016. The technique of collecting the data is by using reading and taking notes. The data is analyzed by using content analysis technique.

Based on the result of the analysis, it is found that the type of lexical cohesion used in Patriotik LPM Batanghari University edition July-September 2016 is 239 data. Those lexical cohesions consist of repetition is 206 , synonym is 5 , antonym is 13 , hyponim is 8 , collocation is 6 , dan equivalency is 1 . The most dominant type from every text is repetition.

Keywords : Texts, Lexical cohesion, magazine

\section{PENDAHULUAN}

Bahasa merupakan alat komunikasi yang sangat penting bagi kehidupan kita. Sebagai manusia dalam sepanjang hidup kita hampir tidak pernah terlepas dari peristiwa komunikasi. Setiap anggota masyarakat dan komunitas tertentu selalu terlibat dalam komunikasi, baik bertindak sebagai komunikator (pembicara atau penulis) maupun sebagai komunikan (mitra-bicara, penyimak, atau pembaca). Peristiwa komunikasi yang berlangsung dalam kehidupan kita menjadi tempat untuk mengungkapkan ide, gagasan, isi pikiran, perasaan, keinginan dan sebagainya. Pemanfaatan potensi bahasa sebagai alat komunikasi dapat dilihat dalam berbagai sendi kehidupan kita di antaranya, dunia pendidikan, pemerintahan, dan media massa. Media massa dapat berupa media 
elektronik maupun cetak yang juga merupakan sarana untuk menyampaikan informasi. Sebagaimana terlihat media cetak merupakan salah satu bentuk dari cara penyampaian informasi secara tertulis, dalam hal ini dapat berupa majalah. Pada saat penulis majalah menyampaikan isi pikirannya terjadilah proses pemindahan informasi yang efisien.

Membicarakan suatu bahasa tidak terlepas membicarakan kategori kebahasaan yaitu wacana. Bahasa berkaitan erat dengan wacana. Wacana merupakan satuan tertinggi dan terlengkap dari kalimat atau klausa. Dalam komunikasi, seringkali para pemakai bahasa dapat menafsirkan sesuatu yang disampaikan oleh pemakai bahasa yang lain dengan penafsiran yang berbeda. Dalam hal ini para pemakai bahasa harus mengenali wacana dengan baik, agar pesan wacana dapat diterima dan tidak menimbulkan salah penafsiran.

Wacana dapat dibedakan menjadi dua, yaitu wacana tulis dan wacana lisan (Martutik, 1999: 3.4).
Penulis tertarik meneliti wacana tulis, karena secara struktur penelitian tentang wacana tulis memudahkan penulis untuk memperoleh datanya.

Istilah untuk menganalisis kepaduan kalimat-kalimat dalam sebuah wacana tulis digunakan penanda kohesi. Kalimat sebagai bagian dari wacana memerlukan penanda kohesi yang tidak hanya sebagai alat penghubung unit struktur, tetapi juga berfungsi semantis. Menurut Halliday dan Hasan (dalam Purwoko, 2008: 134) membedakan beberapa macam kohesi, yakni kohesi yang bersifat gramatikal (grammatical cohesion) dan kohesi yang bersifat leksikal (lexical cohesion). Kemudian Gutwinsky (Sudaryat, 2011: 151) mengemukan juga bahwa "Kohesi mengacu pada hubungan antarkalimat dalam wacana, baik dalam tataran gramatikal maupun dalam tataran leksikal ". Oleh karena itu, penanda kohesi tidak hanya berhubungan dengan bentuk tetapi juga berhubungan dengan makna. Wacana yang kohesif akan membawa pengaruh kejelasan hubungan antara satuan 
bentuk yang satu dengan yang lain sehingga pesan yang ingin disampaikan jelas dan utuh.

Wacana yang mengandung penanda kohesi juga terdapat dalam penulisan media cetak. Salah satu bentuk wacana dalam media cetak adalah majalah kampus LPM Patriotik Universitas Batanghari. penulis memilih majalah Patriotik, karena memuat fenomena yang berkaitan dengan civitas akademika maupun non akademika dan memiliki wilayah publikasi yang terjadi di dalam kampus. Selain itu, majalah Patriotik dikelola oleh dikelola oleh sekumpulan mahasiswa yang tergabung di dalam organisasi yang diampu oleh dosen dan ditulis oleh mahasiswa yang bukan ahli di bidang bahasa.

Penulis juga ingin meneliti unsur kohesi leksikal pada majalah ini, karena ingin mengetahui seberapa besar peran unsur tersebut. Penulis tertarik dengan masalah tersebut karena penelitian di bidang wacana sangat mendapat perhatian dari peneliti ilmu bahasa. Selain itu, berdasarkan studi pendahuluan dengan membaca majalah Patriotik edisi XVI penulis majalah menemukan salah satu variasi unsur kohesi leksikal. Berikut ini merupakan contoh kalimat dengan unsur kohesi leksikal repetisi dan hiponim.

(1) "Unbari memiliki 5 (Lima) Fakultas yang terdiri dari Fakultas Hukum, Ekonomi, Fakultas_Keguruan dan Ilmu Pendidikan (FKIP), Teknik dan Pertanian."

(Patriotik, 2016:1)

Pada contoh diatas, pengulangan kata fakultas digunakan untuk menegaskan berapa banyak faktultas yang ada di Universitas Batanghari (Unbari). Penulis majalah menuliskan kata fakultas hanya pada Fakultas Hukum dan Fakultas Keguruan dan Ilmu Pendidikan. Sedangkan Ekonomi, Teknik, dan Pertanian tidak disebutkan kata fakultas. Selain itu, pada kata Hukum, Ekonomi, Keguruan dan Ilmu $\underline{\text { Pendidikan, }}$ Teknik dan Pertanian merupakan hiponim karena menjelaskan bagian dari fakultas yang ada di Universitas Batanghari. 
Berdasarkan latar belakang tersebut, penulis ingin menjadikan kohesi leksikal dalam majalah Patriotik sebagai karya tulis dalam penelitian akhir dengan judul "Analisis Kohesi Leksikal dalam Majalah Patriotik LPM Universitas Batanghari Edisi XVI Juli-September Tahun 2016".

Artikel ini bertujuan untuk menganalisis unsur kohesi leksikal yang terdapat dalam majalah Patriotik LPM Universitas Batanghari edisi JuliSeptember Tahun 2016.

\section{METODE PENELITIAN}

Artikel ini termasuk penelitian deskriptif kualitatif. Penelitian deskriptif kualitatif merupakan penelitian yang dilakukan berdasarkan pada fakta yang ada atau fenomena secara empiris hidup pada penuturpenuturnya. Menurut Bogdan dan Taylor (dalam Muhammad, 2011:30) mendefinisikan "Penelitian kualitatif sebagai prosedur penelitian yang menghasilkan data deskriptif berupa kata-kata tertulis atau lisan dari orang- orang dan perilaku yang dapat diamati. menurut Sudaryanto (1992: 63) "Pendekatan deskriptif adalah pendekatan yang lebih menandai pada hasil penelitian yang bersangkutan dengan bahasa dengan cara menandai cara penggunaan bahasa terhadap demi tahap, langkah demi langkah". Adapun penelitian kualitatif berdekatan dengan data yang tidak berupa angka-angka, tetapi berupa bentuk bahasa.

\section{HASIL PENELITIAN DAN}

\section{PEMBAHASAN}

\section{Repetisi}

Menurut Martutik (1999: 3.29) Repetisi atau ulangan merupakan salah satu hubungan kohesif. Macam-macam repetisi berdasarkan pemakaiannya dalam bahasa Indonesia adalah sebagai berikut.

1. Ulangan Penuh: Ulangan penuh berarti mengulang satu fungsi dalam kalimat secara penuh tanpa pengurangan dan perubahan bentuk.

2. Ulangan dengan bentuk lain: Ulangan dengan bentuk lain terjadi bila sebuah kata diulang dengan 
konstruksi atau bentuk kata lain yang masih mempunyai bentuk dasar yang sama.

3. Ulangan dengan penggantian: Ulangan dengan penggantian sama dengan penggunaan kata ganti (substitusi).

Berikut ini unsur kohesi leksikal repetisi yang terdapat dalam majalah Patriotik.

(1) Universitas Batanghari sejak awal berdirinya tahun 1985 sampai saat ini dibina oleh dan bernaung di bawah Yayasan Pendidikan Jambi. Yayasan ini merupakan pengembangan dari Yayasan

Pendidikan Jambi yang dulunya membina STKIP Jambi pada tahun 1970-1977. Pada tahun 2015 sampai 2016 jumlah mahasiswa dari semua Fakultas yang ada berjumlah 5.061 berdasarkan website resmi Unbari (unbari.ac.id). (Patriotik, 2016:1)

Pada data (1) terdapat pengulangan kata sampai, Yayasan Pendidikan Jambi, pada tahun, dan jumlah. Pada kata sampai, Yayasan Pendidikan Jambi, pada tahun merupakan bentuk ulangan penuh. Sedangkan pada kata jumlah termasuk nomina. Kata tersebut diulang dengan kontruksi berjumlah yang kategorinya verba yang mengalami nominalisasi sebagai subjek. Kata tersebut termasuk ulangan dengan bentuk kata lain.

\section{Sinonim}

Menurut Verhaar (dalam Pateda, 2001:223) mengatakan "Sinonimi adalah ungkapan (biasanya sebuah kata tetapi dapat pula frasa atau malah kalimat) yang kurang lebih sama maknanya dengan suatu ungkapan lain. Berikut ini kohesi leksikal sinonim yang terdapat dalam majalah Patriotik.

(2) Ketika membahas mengenai jurnalistik, pikiran kita tentu akan langsung tertuju pada kata berita atau mengenai wartawan, Pers Mahasiswa adalah Jurnalis Kampus, seperti itu lah sebutan bagi para wartawan yang mencari pemberitaan di ruang lingkup kampus.

(Patriotik, 2016:13)

Pada data (2) terdapat sinonim kata wartawan dan jurnalis, karena keduanya memiliki makna seseorang yang bertugas mencari dan menulis 
berita. Berdasarkan kenyataannya, pasangan kata yang bersifat sinonim sulit ditemukan. Dengan demikian dapat dirumuskan pula bahwa tidak ada kata yang mutlak sama.

\section{Antonim}

Menurut Keraf (2010: 39), Antonim adalah relasi antar makna yang wujud logisnya sangat berbeda atau bertentangan. Walaupun kita menerima konsep antonim secara umum, sebenarnya terdapat perbedaan antara bermacam-macam kata yang berantonim itu. Oposisi dapat berbentuk (Keraf, 2010: 40-41):

1. Oposisi kembar: oposisi yang mencakup dua anggota. Seperti laki-laki-wanita, jantan-wanita.

2. Oposisi majemuk: oposisi yang mencakup suatu perangkat yang terdiri dari dua kata. Seperti logam, spesies binatang, tumbuhtumbuhan, buah-buahan, dan warna.

3. Oposisi gradual: kelas ini sebenarnya suatu penyimpangan dari oposisi kembar, yaitu antara dua istilah yang berlawanan masih terdapat sejumlah tingkatan antara. Antara kaya dan miskin, besarkecil.
4. Oposisi relasional (kebalikan):adalah oposis antara dua kata yang mengandung relasi kebalikan. Seperti pembeli-penjual, memberi-menerima.

5. Oposisi hirarkis: oposisi yang terjadi karena tiap istilah menduduki derajat berlainan. Seperti inci-yard, JanuariFebruari-Maret-April.

6. Oposisi inversi: oposisi yang terdapat pada pasangan kata seperti: beberapa-sетиa, boleh-harus, tetap-menjadi.

Berikut ini kohesi leksikal antonim yang terdapat dalam majalah Patriotik.

(3) Hadir dalam acara tersebut Perwakilan Gubernur Jambi, Forum Komunikasi Pimpinan Daerah (FORKOMPIMDA) Provinsi Jambi, Bupati dan Walikota di Wilayah Provinsi Jambi , Ketua Yayasan Pendidikan Jambi, Koordinator Kopertis Wilayah X, Pimpinan Perguruan Tinggi Negeri dan Swasta di lingkungan Kota Jambi, Kepala SKPD, Kepala Badan dilingkungan Pemda Provinsi Jambi, Anggota Senat Universitas Batanghari, Dosen dan tenaga administrasi di lingkungan Unbari, serta Para Orang Tua dan keluarga wisudawan/wisudawati.

(Patriotik, 2016:5) 
Pada data (3) terdapat dua antonim, yaitu, 1) kata swasta dan negeri, dan 2) kata wisudawan dan wisudawati. Pada kata swasta dan negeri merupakan antonim oposisi hierarkis. Kata swasta menunjukkan suatu instansi atau lembaga milik perorangan atau kelompok. Sedangkan kata negeri bias menunjukan suatu instansi milik pemerintah atau negera. Selanjutnya pada kata wisudawan dan wisudawati merupakan antonim oposisi kembar. Mengacu pada pernyataan Keraf (2010: 39) oposisi kembar mencakup dua anggota.

\section{Hiponim}

Menurut Verhaar (dalam Pateda, 2001: 209), Hiponim ialah ungkapan (kata, biasanya atau kiranya dapat juga frasa atau kalimat) yang maknanya dianggap bagian dari makna suatu ungkapan lain. berikut ini kohesi leksikal hiponim yang terdapat dalam majalah Patriotik.

(4) Sering kali olahraga merupakan kegiatan yang dilupakan, padahal dengan olahraga dapat melancarkan peredaran darah dan menghindarkan tubuh dari serangan ke berbagai penyakit.
Sempatkanlah olahraga ringan minimal jalan kaki 2-3 jam di pagi hari karena dengan olahraga ringan tersebut sudah cukup menghindarkan tubuh dari penyakit jantung, stroke, diabetes dan osteoporosis.

(Patriotik, 2016:19)

Pada data (4) terdapat hiponim kata Jantung, stroke, diabetes, dan osteoporosis, karena bagian subordinat dari leksem penyakit.

\section{Kolokasi}

Menurut Martutik (1999: 3.31) megatakan bahwa, kolokasi adalah sesuatu hal yang selalu berdekatan atau berdampingan dengan yang lain biasanya diasosiakan sebagai satu kesatuan. Berikut ini kohesi leksikal kolokasi yang terdapat dalam majalah Patriotik.

(5) Tak hanya rektorat yang sedang bersiap menyambut mahasiswa baru, namun juga pihak keamanan, yang memberikan suaranya kepada Patriotik. Kepala Satuan Keamanan Kampus (SKK) Unbari, Pak Sayuti mengatakan, yang terpenting dalam penyambutan Maru adalah mengarahkan mahasiswa baru untuk parkir pada 
tempat yang telah disediakan, agar

mahaisswa baru bisa membedakan antara parkiran dosen, karyawan, dan parkiran mahasiswa.

(Patriotik, 2016:3)

Pada data (5) kata Rektorat, dosen, karyawan dan mahasiswa merupakan kolokasi, karena berada di ruang lingkup kampus atau masyarakat akademik.

\section{Ekuivalensi}

Ekuivalensi adalah penggunaan kata-kata yang memiliki kemiripan makna atau maknanya berdekatan (Sudaryat, 2011:162). Berikut ini kohesi leksikal ekuivalensi yang terdapat dalam majalah Patriotik.

(6) Visi adalah keinginan kita untuk yang akan datang, dalam proses ini kita bertahap-tahap untuk menjalankan apa yang akan menjadi tujuan kampus ini kedepannya, ketika Patriotik menanyakan dalam visi Unbari yaitu kata berakhlak mulia, beliau juga mengatakan, dalam arti agama bagus serta yang lainnya, banyak mahasiswa yang mempunyai ilmu tinggi tapi tidak berakhlak mulia, dalam hal ini yang sangat berpengaruh yaitu dosen yang mengajar mata kuliah agar memberikan waktu untuk mengarahkan mahasiswa untuk belajar tentang akhlak mulia dengan baik.

(Patriotik, 2016:1)

Pada data (6) terdapat ekuivalensi kata dosen memiliki kedekatan makna atau identik dengan mengajar. Bukan hanya mengajar tentang ilmu pengetahuan tetapi mengarahkan mahasiswa tentang akhlak mulia dengan baik.

\section{KESIMPULAN DAN SARAN}

\section{Kesimpulan}

Berdasarkan hasil penelitian dan pembahasan yang telah dilakukan dapat diambil kesimpulan sebagai berikut.

a. Unsur kohesi leksikal yang terdapat dalam majalah Patriotik LPM Universitas Batanghari Edisi XVI Juli-September Tahun 2016 terdiri dari, repetisi, sinonim, antonim, hiponim, kolokasi, dan ekuivalensi. Sementara itu, tiaptiap wacana didominasi oleh unsur kohesi leksikal repetisi. 
b. Unsur kohesi leksikal yang terdapat dalam majalah Patriotik LPM Universitas Batanghari Edisi XVI Juli-September Tahun 2016 sebanyak 239 kutipan, yang terdiri dari repetisi berjumlah 206 kutipan, sinonim 5 kutipan, antonim 13 kutipan, hiponim 8 kutipan, kolokasi 6 kutipan, dan ekuivalensi 1 kutipan.

2. Saran

a. Adanya unsur kohesi leksikal dalam setiap tulisan sangat penting, sehingga harus diperhatikan berdasarkan struktur/kaidah kebahasaan. Agar terbentuk kepaduan antarunsur yang baik dan mudah dipahami oleh pembaca.

b. Sebaiknya mahasiswa meningkatkan pengetahuan tentang unsur kohesi leksikal, khususnya bagi pembelajaran menulis. Hal ini dimaksudkan agar tulisan mahasiswa memiliki tingkat kekohesifan dengan baik sehingga dapat meningkatkan hasil karya tulis ilmiah mahasiswa. c. Penelitian tentang analisis unsur kohesi leksikal dalam majalah Patriotik masih banyak fenomena kebahasaan yang dapat diteliti dengan penggunaan kohesi. Salah satunya berkenaan dengan bagian spesifik pembentuk unsur leksikal dalam kohesi. Oleh karena itu, bagi peneliti selanjutnya dapat mengkaji struktur wacana yang lebih mendasar, tidak hanya dari segi kohesi leksikal.

\section{DAFTAR PUSTAKA}

Keraf, Gorys. 2010. Diksi dan Gaya Bahasa. Jakarta: PT Ikrar Mandiriabadi

Martutik, Suparno. 1999. Wacana Bahasa Indonesia. Jakarta. Departemen Pendidikan dan Kebudayaan

Muhammad. 2011. Metode Penelitian Bahasa. Jakarta: AM ArRuzzMedia

Pateda, Mansoer. 2001. Semantik Leksikal. Jakarta: Rineka Cipta 
Jurnal AKSARA : Jurnal IImiah Pendidikan Bahasa dan Sastra Indonesia Vol.1 No.1 September 2017

Purwoko, Herudjati. 2008. Discourse Analysis Kajian Wacana bagi Semua Orang. Jakarta: Indeks

Sudaryat, Yayat. 2011. Makna dalam Wacana Prinsip-Prinsip Semantik dan Pragmatik. Bandung: Yrama Widya
Sudaryanto, 2005. Metode dan Aneka Teknik Analisis Bahasa. Yogyakarta: Universitas Sanata Dharma 